\title{
How long does it take to perform emergency ultrasound for the primary indications?
}

\author{
Steven Socransky $\cdot$ Ray Wiss $\cdot$ Gary Bota $\cdot$ \\ Teresa Furtak
}

Received: 13 July 2010/ Accepted: 26 October 2010/Published online: 16 November 2010

(C) Springer-Verlag 2010

\begin{abstract}
Purpose Although emergency ultrasound (EU) is gaining popularity, EU is performed in a minority of emergency departments (EDs). The perception may exist that EU is too time-consuming. This study sought to determine the duration of EUs performed for the primary indications by staff emergency physicians (EPs).

Methods A prospective, time-motion study was conducted on a convenience sample of EUs at the Sudbury Regional Hospital ED from June to August 2006. All EPs had Canadian EU certification. A research assistant timed EUs. Primary EU indications in Canada are: cardiac arrest evaluation, rule-out pericardial effusion, rule-out intraperitoneal free fluid in trauma, rule-out abdominal aortic aneurysm, and rule-in intrauterine pregnancy. Descriptive statistics are reported.

Results Eleven EPs performed 66 EUs for the primary indications on 51 patients. The mean EU duration was $137.8 \mathrm{~s}$ (range 11-465; CI 123.0-162.6). There was no difference in the duration of EUs performed by the two most experienced EPs $(n=37$; duration $=129.4$; $\mathrm{CI}=96.4-162.4)$ compared to the other EPs $(n=29$; duration $=148.4 ; \quad$ CI $=110.6-186.2) . \quad$ Although subgroups were small, positive $(n=8$; duration $=199.4$; $\mathrm{CI}=97.4-301.4)$, negative $(n=49 ;$ duration $=123.3$; $\mathrm{CI}=97.9-148.7)$, and indeterminate $(n=9$; duration $=$ 161.6; CI $=91.5-231.7$ ) EUs did not differ in duration. There is some suggestion of differences in duration between types of EU, although again the subgroups were
\end{abstract}

S. Socransky $(\bowtie) \cdot$ R. Wiss $\cdot$ G. Bota $\cdot$ T. Furtak Emergency Department, Sudbury Regional Hospital, 41 Ramsey Lake Road, Sudbury, ON P3E 5J1, Canada e-mail: ssocransky@sympatico.ca small: cardiac $(n=21$; duration $=90.3 ; \mathrm{CI}=62.6-118.0)$, abdominal $(n=22 ;$ duration $=157.1 ; \mathrm{CI}=111.9-202.3)$, aneurysm $(n=15$; duration $=170.1 ; \mathrm{CI}=117.5-222.7)$, transabdominal pelvic $(n=5$; duration $=89.8 ; \mathrm{CI}=40.3-$ 139.1), transvaginal $(n=3$; duration $=246.0 ; \mathrm{CI}=30.6$ 461.4).

Conclusion When performed by staff EPs with EU certification, mean EU duration for the primary indications was brief regardless of EP's experience, EU type, or results.

Keywords Ultrasonography - Emergency medicine . Canada $\cdot$ Time and motion studies

\section{Introduction}

Evidence continues to mount that emergency ultrasound (EU) expedites critical diagnoses [1-4] and facilitates the performance of invasive procedures [5-7]. Emergency department (ED) throughput is enhanced by EU [8-10]. Furthermore, EU can be performed competently by nonradiologists after focused training [11-15]. Not surprisingly, the use of bedside EU continues to grow in academic EDs. Moore et al. [16] reported that $92 \%$ of academic EDs in the USA have EU $24 \mathrm{~h}$ per day.

Despite this, the prevalence of EU in community EDs has lagged. Stein et al. [17] found that only $29 \%$ of community EDs in California were using EU. Similarly, Woo [18] found that only $29 \%$ of EDs in New Zealand had access to EU. In Ontario, ultrasound-guided central venous line placement is only performed in a minority of EDs [19]. The perception may exist that $\mathrm{EU}$ is too time-consuming to perform during a busy shift. If true, this perception may be an impediment to the incorporation of EU into emergency 
physician (EP) practice. Further, the time required to perform EU may not be accounted for in ED staffing patterns. Present and future ED staffing may be determined by timemotion studies which do not include the time required to perform EU [20, 21]. Thus, information regarding the time needed to perform EU would be useful.

Several studies have reported on the time required to perform bedside ultrasound by non-radiologists, both EPs and trauma surgeons [22-34]. However, all of these studies have problems with their results including only one type of EU performed [22, 24-34], self-reported estimates of time required $[28,30,32,33]$ and only residents with limited training performing EU $[23,28,30,31,33]$. To date, no study has reliably recorded the time required by physicians certified in EU to perform EU across all primary indications. In Canada, the primary EU indications as established by the Canadian Emergency Ultrasound Society (CEUS) are (1) cardiac activity evaluation in the setting of cardiac arrest, (2) rule-out pericardial effusion, (3) rule-out intraperitoneal free fluid in trauma, (4) rule-out abdominal aortic aneurysm, and (5) rule-in intrauterine pregnancy. The objective of this study was to determine EU exam duration for the primary indications when performed by staff EPs certified in EU.

\section{Methods}

Study design

This was a prospective, time-motion study conducted on a convenience sample of patient-physician interactions where an EU examination was performed. Approval was obtained from the Research Ethics committee of Hôpital regional de Sudbury Regional Hospital (HRSRH). Verbal consent was obtained from all patients.

Study setting and population

The study took place in the HRSRH ED from June to August 2006. The HRSRH ED is the sole ED for Sudbury which has a metropolitan population of 160,000 . Annual ED volume is approximately 60,000 . HRSRH serves as the trauma and tertiary care centre for Northeastern Ontario. All but 1 of the 24 EPs has certification in emergency medicine with either the College of Family Physicians of Canada or the Royal College of Physicians and Surgeons of Canada. The majority of EPs are certified in EU as per the criteria established by CEUS [35]. At the time of the study, two of the study authors (SJS, RW) had performed in excess of 1,000 EU exams, far more than the other EPs. The ED is the base hospital for an emergency medicine residency programme under the
College of Family Physicians of Canada. However, the large majority of patients are seen primarily by a staff EP.

Two ultrasound machines are employed in the ED: a Siemens Sonoline Adara (Siemens AG, Erlangen, Germany) and a Sonosite Micromaxx (Sonosite Inc, Bothell, WA, USA). In most cases of a negative or indeterminate result, documentation of EU exam results is limited to a written note in the patient chart. When an EU exam is positive, an image (printed or digital) or video is often recorded. The abdominal EU for trauma includes views of the hepatorenal space, the splenorenal space, and a suprapubic view (transverse and/or longitudinal). The aortic EU is typically limited to the transverse view. The cardiac EU is typically limited to the subcostal view. A pelvic EU may start with a transabdominal (longitudinal and/or transverse view) or transvaginal (sagittal and/or coronal view) EU exam, depending on the clinical circumstance and EP preference. An unequivocally positive abdominal EU exam for trauma may result in some views not being completed. All views are completed in the setting of a negative EU exam. In the case of an unequivocally positive pelvic EU exam (i.e. definitive intrauterine pregnancy), the EP may not always complete both a transabdominal and transvaginal exam. Negative exams are based on CEUS criteria [35]. Exams are deemed indeterminate if adequate views of the area of interest cannot be obtained or if the findings are equivocal.

\section{Study protocol}

One research assistant (RA) was available for this study. The RA was scheduled to work 9-h day or evening shifts on weekdays and weekends throughout June-August 2006 when at least one CEUS-certified staff EP was working. Inclusion criteria were EU examinations performed by a CEUS-certified EP for one of the following primary indications: cardiac arrest evaluation, rule-out pericardial effusion, rule-out intraperitoneal free fluid in trauma, rule-out abdominal aortic aneurysm, and rule-in intrauterine pregnancy. EU examinations performed for other diagnostic indications were not included. EU exams done by non-certified EPs and residents were excluded.

Measurements or key outcome measures

A stopwatch was used by the RA to time the exam duration. The stopwatch was started when the EP first interacted with either the machine or the patient in preparation for the EU exam. Examples of machine interaction included plugging in the machine, turning it on, adjusting a machine setting, or picking up a probe. Examples of patient 
interaction included exposing an area to be examined or applying ultrasound gel. The EP or ancillary personnel moved the ultrasound machine to the patient bedside. The time required to move the machine was not included in the exam duration. Patient and machine clean-up were not included in the exam duration. When one patient had two or more EU exams for the primary indications (e.g. abdominal and cardiac), each exam was timed separately. In such cases, the end of the first EU exam and the beginning of the second EU exam was recorded as the point in time when the probe was taken off the patient skin for the first EU exam. Similarly, when one patient had a transvaginal and transabdominal pelvic EU exam performed, each exam was timed separately.

\section{Data analysis}

Patient and study data were documented contemporaneously in a standardized manner on a Microsoft Excel spreadsheet (Microsoft Corporation, Redmond, WA). Descriptive statistics including EU exam duration mean, range, and confidence intervals are reported in seconds. The impact of physician experience on EU duration was determined using the Student's $t$ test. The impact of the exam type and exam results on EU duration was determined using analysis of variance. Statistical analyses were performed using SPSS 17.0 (SPSS Inc., Chicago, IL).

\section{Results}

Eleven EPs performed 66 EU exams for the primary indications on 51 patients. The mean EU duration was $137.8 \mathrm{~s}$ (range $11-465 ; 95 \% \mathrm{CI}=112.5-163.0$ ). There was no significant difference $(p=0.922)$ in the mean duration of EU exams performed by the two most experienced EPs $(n=37$; duration $=129.4$; 95\% CI $=96.4$ 162.4) compared to the other EPs $(n=29$; duration $=$ 148.4; 95\% CI $=110.6-186.2$ ). Although subgroups were small, the duration of positive $(n=8$; duration $=199.4$; 95\% CI $=76.3-322.5)$, negative $(n=49 ;$ duration $=$ 123.3; 95\% CI $=97.3-149.4)$, and indeterminate $(n=9$; duration $=161.6 ; 95 \% \mathrm{CI}=79.1-244.1) \mathrm{EU}$ exams did not differ significantly $(p=0.114)$. There was a non-significant trend towards a difference in mean duration between types of EU, although again the subgroups were small: cardiac $(n=21$; duration $=90.3 ; 95 \% \mathrm{CI}=60.8$ 119.8), abdominal $(n=22$; duration $=157.1 ; 95 \% \mathrm{CI}=$ 109.1-205.1), aneurysm $(n=15$; duration $=170.1 ; 95 \%$ $\mathrm{CI}=112.5-227.7)$, transabdominal pelvic $(n=5$; duration $=89.8 ; 95 \% \mathrm{CI}=19.9-159.7)$, transvaginal $(n=3$; duration $=246.0 ; 95 \% \mathrm{CI}=0-718.9$ ).

\section{Discussion}

Despite the proven benefits of EU, it is only used in a minority of EDs [17-19]. Since formal ultrasound often requires $30 \mathrm{~min}$ or more to perform, many EPs may have the perception that EU is too time-consuming to incorporate into their clinical practice. Contrary to this perception, this study has shown that EU exams only require a mean of $2 \mathrm{~min}, 17 \mathrm{~s}$ to perform. Therefore, the authors believe that EU exam duration should not represent an impediment to the incorporation of EU into emergency medical practice. Furthermore, one does not need to be an expert to perform EU efficiently. The EPs with the most experience in our group performed EU exams only $19 \mathrm{~s}$ faster than the rest of the EPs. This is a clinically and statistically insignificant difference. Despite the brevity of this exam, determinate results were obtained in 57 of $66 \mathrm{EU}$ cases.

The duration of positive, negative and indeterminate $\mathrm{EU}$ exams did not differ significantly. As well, there was no statistically significant difference in the duration of the various EU exam types. However, the subgroups were small. There was a trend towards indeterminate scans requiring more time to complete. As well, there was a trend towards cardiac and transabdominal pelvic scans being briefer, and transvaginal being a longer scan. Larger subgroups would be required to make a firm conclusion.

This is the first study to accurately measure the time required by physicians certified in EU to perform EU across all primary indications. Only one prior study has previously measured EU exam duration for all of the primary indications [23]. All other studies have focused on trauma [24-27, 29-34] or deep venous thrombosis (DVT) $[22,28]$. Only three studies have included EU exams performed only by non-radiologist staff physicians and not trainees [22, 26, 34].

Prior studies [22-34] have reported a wide range of EU durations [22-34]. Only three studies have reported an EU duration in excess of $5 \mathrm{~min}$ [23, 27, 28]. Blaivas [23] reported that residents required a mean of $9 \mathrm{~min}, 53 \mathrm{~s}$ to perform EU. Healey reported that a comprehensive trauma scan required a mean of $10.1 \mathrm{~min}$ to perform. However, the scan was performed by an ultrasound technician and interpreted by a trauma surgeon. Jang reported that residents with limited training required a mean of $11.7 \mathrm{~min}$ to perform a DVT scan. In contrast, Blaivas [22] reported that a DVT scan performed by physicians with significant experience required a median of only $3 \mathrm{~min}, 28 \mathrm{~s}$.

Four other studies have reported EU exam durations of less than 3 min [24, 25, 31, 34]. Only the trauma scan was the subject of these studies. One of these studies [25] found that EU duration reached a plateau of just over 2 min once the physicians completed 50-75 exams. The reliability of EU duration measurement has varied in previous studies. 
Only two studies used a stopwatch to time the EU exam $[22,23]$. In three studies [24, 25, 34], all from the same centre, the duration was estimated using the duration of the videocassette recording of the scan. Self-reported estimates were used in four studies [28, 30, 32, 33]. Four studies did not report their method of measurement [26, 27, 29, 31].

\section{Limitations and future questions}

Several tasks associated with EU were not included in EU duration measurement. The time required to bring the machine to the patient bedside was not included in the duration. In our ED, ancillary personnel usually perform this task. Machine cleanup typically only requires a few seconds to perform. A more extensive cleaning of the endocavitary probe is performed by ancillary personnel. Documentation is usually limited to a written note in the chart and only takes a few seconds. In other jurisdictions, documentation requirements may be more extensive and timeconsuming. The standard views performed for the primary indications may be fewer in Canada than in other countries and may limit the generalizability of these results.

It is possible that the physicians altered how they performed bedside ultrasound when being timed (i.e. Hawthorne bias). Individual physicians may have performed scans more quickly or slowly than usual when being timed. Physicians could not be blinded to the timing of their scans. Lastly, funding was sufficient to hire only one RA. It is possible that a second RA would have obtained different scan durations.

We did not measure the duration of EU exams performed for indications other than the primary indications. The duration of other EU exams (gallstones, hydronephrosis, etc.) could be the subject of a future study. As EU continues to disseminate throughout emergency medicine, more EU exams (primary and advanced applications) will be performed. Although individual EU exams may be brief, the impact of EU growth on EP staffing will need to be assessed.

\section{Conclusions}

When performed by staff EPs certified in EU, the mean duration of the EU exam across all primary indications is $2 \mathrm{~min}, 17 \mathrm{~s}$. The duration of the EU exam is sufficiently brief to allow EU incorporation into a busy emergency medical practice. Future research should focus on other potential impediments to the dissemination of EU.

Acknowledgment The authors would like to thank Vic Sahai for his expert statistical assistance.

Conflicts of interest None.

\section{References}

1. Scalea TM, Rodriguez A, Chiu WC et al (1999) Focused assessment with sonography for trauma (FAST): results from an international consensus conference. J Trauma 46:466-472

2. Blaivas M (2001) Incidence of pericardial effusion in patients presenting to the emergency department with unexplained dyspnea. Acad Emerg Med 8:1143-1146

3. Mateer JR, Valley VT, Aiman EJ et al (1996) Outcome analysis of a protocol including bedside endovaginal sonography in patients at risk for ectopic pregnancy. Ann Emerg Med 27:283-289

4. Kuhn M, Bonnin RL, Davey MJ et al (2000) Emergency department ultrasound scanning for abdominal aortic aneurysm: accessible, accurate, and advantageous. Ann Emerg Med 36:219-223

5. Hind D, Calvert N, McWilliams R et al (2003) Ultrasonic locating devices for central venous cannulation: meta-analysis. BMJ 327:361

6. Mayo PH, Goltz HR, Tafreshi M, Doelken P (2004) Safety of ultrasound-guided thoracentesis in patients receiving mechanical ventilation. Chest 125:1059-1062

7. Roy S, Dewitz A, Paul I (1999) Ultrasound-assisted ankle arthrocentesis. Am J Emerg Med 17:300-301

8. Schlager D, Whitten D, Tolan K (1997) Emergency department ultrasound: impact on ED stay times. Am J Emerg Med 15:216-217

9. Blaivas M, Sierzenski P, Plecque D, Lambert M (2000) Do emergency physicians save time when locating a live intrauterine pregnancy with bedside ultrasonography? Acad Emerg Med 7:988-993

10. Shih CH (1997) Effect of emergency physician-performed pelvic sonography on length of stay in the emergency department. Ann Emerg Med 29:348-351

11. Gracias VH, Frankel HL, Gupta R et al (2001) Defining the learning curve for the focused abdominal sonogram for trauma (FAST) examination: implications for credentialing. Am Surg 67:364-368

12. Lanoix R, Leak LV, Gaeta T, Gernsheimer JR (2000) A preliminary evaluation of emergency ultrasound in the setting of an emergency medicine training program. Am J Emerg Med 18:41-45

13. Mandavia DP, Aragona J, Chan L et al (2000) Ultrasound training for emergency physicians-a prospective study. Acad Emerg Med 7:1008-1014

14. Shackford SR, Rogers FB, Osler TM et al (1999) Focused abdominal sonogram for trauma: the learning curve of nonradiologist clinicians in detecting hemoperitoneum. J Trauma 46:553-562

15. Thomas B, Falcone RE, Vasquez D et al (1997) Ultrasound evaluation of blunt abdominal trauma: program implementation, initial experience, and learning curve. J Trauma 42:384-388

16. Moore CL, Gregg S, Lambert M (2004) Performance, training, quality assurance, and reimbursement of emergency physicianperformed ultrasonography at academic medical centers. J Ultrasound Med 23:459-466

17. Stein JC, River G, Kalika I et al (2009) A survey of bedside ultrasound use by emergency physicians in California. J Ultrasound Med 28:757-763

18. Woo M (2003) Availability of urgent ultrasonography to emergency departments in New Zealand. N Z Med J 116:U401

19. Socransky SJ, Wiss R, Bourdon C, Furtak T (2007) Ultrasoundguided central venous line placement: a survey of Ontario's Emergency Department Medical Directors. Paper presented at the 3rd World Congress on Ultrasound in Emergency and Critical Care Medicine, Paris, France, 9-11 May 2007 
20. Graff LG, Dinwoodie R, Buono D, Mucci D (1993) Emergency physician workload: a time study. Ann Emerg Med 22:1156-1163

21. Innes GD, Stenstrom R, Grafstein E, Christenson JM (2005) Prospective time study derivation of emergency physician workload predictors. Can J Emerg Med 7:299-308

22. Blaivas M, Lambert MJ, Harwood RA, Wood JP, Konicki J (2000) Lower-extremity Doppler for deep venous thrombosiscan emergency physicians be accurate and fast? Acad Emerg Med 7:120-126

23. Blaivas M, Theodoro D (2003) Comparison of perceived and actual times spent by residents performing ultrasound examinations on patients. Acad Emerg Med 10:397-399

24. Boulanger BR, Brenneman FD, McLellan BA et al (1995) A prospective study of emergent abdominal sonography after blunt trauma. J Trauma 39:325-330

25. Boulanger BR, McLellan BA, Brenneman FD et al (1996) Emergent abdominal sonography as a screening test in a new diagnostic algorithm for blunt trauma. J Trauma 40:867-874

26. Goletti O, Ghiselli G, Lippolis PV et al (1994) The role of ultrasonography in blunt abdominal trauma: results in 250 consecutive cases. J Trauma 369:178-181

27. Healey MA, Simons RK, Winchell RJ et al (1996) A prospective evaluation of abdominal ultrasound in blunt trauma: is it useful? J Trauma 40:875-883

28. Jang T, Docherty M, Aubin C, Polites G (2004) Resident-performed compression ultrasonography for the detection of proximal deep venous thrombosis: fast and accurate. Acad Emerg Med 11:319-322

29. Lucciarini P, Ofner D, Weber F, Lungenschmid D (1993) Ultrasonography in the initial evaluation and follow-up of blunt abdominal injury. Surgery 114:506-512

30. Ma OJ, Mateer JR, Ogata M et al (1995) Prospective analysis of a rapid trauma ultrasound examination performed by emergency physicians. J Trauma 38:879-885

31. Rozycki GS, Ochsner MG, Schmidt JA et al (1995) A prospective study of surgeon-performed ultrasound as the primary adjuvant modality for injured patient assessment. J Trauma 39:492-498

32. Sarkisian AE, Khondkarian RA, Amirbekian NM et al (1991) Sonographic screening of mass casualties for abdominal and renal injuries following the 1988 Armenian earthquake. J Trauma 31:247-250

33. Thourani VH, Pettitt BJ, Schmidt JA et al (1998) Validation of surgeon-performed emergency abdominal ultrasonography in pediatric trauma patients. J Pediatr Surg 33:322-327

34. Wherrett LJ, Boulanger BR, McLellan BA et al (1996) Hypotension after blunt abdominal trauma: the role of emergent abdominal sonography in surgical triage. J Trauma 41:815-820

35. Canadian Emergency Ultrasound Society website (2010) http://www.ceus.ca/002-standards/002-00.standards.htm. Accessed 1 May 2010 